2006s-02

\title{
Input Specificity and Global Sourcing
}

\author{
Galina A. Schwartz, Ari Van Assche
}

\begin{tabular}{c}
\hline Série Scientifique \\
Scientific Series
\end{tabular}

Montréal

Février 2006

(C) 2006 Galina A. Schwartz, Ari Van Assche. Tous droits réservés. All rights reserved. Reproduction partielle permise avec citation du document source, incluant la notice $\mathbb{C}$.

Short sections may be quoted without explicit permission, if full credit, including (C) notice, is given to the source.
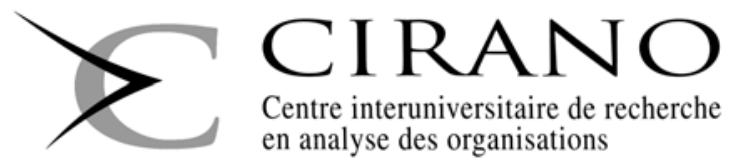

Centre interuniversitaire de recherche en analyse des organisations 


\section{CIRANO}

Le CIRANO est un organisme sans but lucratif constitué en vertu de la Loi des compagnies du Québec. Le financement de son infrastructure et de ses activités de recherche provient des cotisations de ses organisations-membres, d'une subvention d'infrastructure du Ministère du Développement économique et régional et de la Recherche, de même que des subventions et mandats obtenus par ses équipes de recherche.

CIRANO is a private non-profit organization incorporated under the Québec Companies Act. Its infrastructure and research activities are funded through fees paid by member organizations, an infrastructure grant from the Ministère du Développement économique et régional et de la Recherche, and grants and research mandates obtained by its research teams.

PARTENAIRE MAJEUR

\section{Les organisations-partenaires / The Partner Organizations}

. Ministère du Développement économique, de l'Innovation et de l'Exportation

PARTENAIRES

. Alcan inc.

. Banque du Canada

. Banque Laurentienne du Canada

. Banque Nationale du Canada

. Banque Royale du Canada

. Bell Canada

. BMO Groupe financier

. Bombardier

. Bourse de Montréal

. Caisse de dépôt et placement du Québec

. Fédération des caisses Desjardins du Québec

- GazMétro

. Hydro-Québec

. Industrie Canada

. Ministère des Finances du Québec

. Pratt \& Whitney Canada

. Raymond Chabot Grant Thornton

. Ville de Montréal

. École Polytechnique de Montréal

. HEC Montréal

. Université Concordia

. Université de Montréal

. Université du Québec

. Université du Québec à Montréal

. Université Laval

. Université McGill

. Université de Sherbrooke

AssociÉ À :

. Institut de Finance Mathématique de Montréal (IFM²)

. Laboratoires universitaires Bell Canada

. Réseau de calcul et de modélisation mathématique $\left[\mathrm{RCM}^{2}\right]$

. Réseau de centres d'excellence MITACS (Les mathématiques des technologies de l'information et des systèmes complexes)

Les cahiers de la série scientifique (CS) visent à rendre accessibles des résultats de recherche effectuée au CIRANO afin de susciter échanges et commentaires. Ces cahiers sont écrits dans le style des publications scientifiques. Les idées et les opinions émises sont sous l'unique responsabilité des auteurs et ne représentent pas nécessairement les positions du CIRANO ou de ses partenaires.

This paper presents research carried out at CIRANO and aims at encouraging discussion and comment. The observations and viewpoints expressed are the sole responsibility of the authors. They do not necessarily represent positions of CIRANO or its partners. 


\title{
Input Specificity and Global Sourcing
}

\author{
Galina A. Schwartz ${ }^{*}$, Ari Van Assche
}

\begin{abstract}
Résumé / Abstract
Cet article étudie le rôle de la productivité sur les choix organisationnels des entreprises. Nous élargissons l'étude d'Antràs et Helpman (2004) en permettant aux entreprises hétérogènes de choisir entre l'adoption d'intrants spécifiques ou génériques. Au sein des industries caractérisées par une forte utilisation d'intrants, les entreprises font face à un compromis entre une productivité réduite liée aux intrants génériques et un problème de hold-up moindre découlant de l'impartition générique. Nous démontrons que le problème de hold-up lié à l'impartition générique augmente selon la productivité d'une entreprise. Ce qui implique que : les entreprises dont le taux de productivité est élevé choisissent l'impartition optimale au Sud, (ii) les entreprises dont le taux de productivité est moyen choisissent l'impartition générique au Sud, (iii) les entreprises dont le taux de productivité est bas choisissent l'impartition générique au Nord.
\end{abstract}

Mots clés : spécificité des intrants, impartition, hétérogénéité des entreprises, incomplétude des contrats, problèmes de hold-up.

This paper investigates the role of productivity on a firm's organizational choice. We expand Antràs and Helpman (2004) by allowing heterogeneous firms to choose between adopting specific and generic inputs. In input-intensive industries, firms face a trade-off between the lower productivity of generic inputs and the reduced hold-up friction of generic outsourcing. We demonstrate that the hold-up friction under generic outsourcing increases with a firm's productivity. This implies that: (i) high productivity firms choose ideal outsourcing to the South, (ii) medium productivity firms choose generic outsourcing to the South, (iii) low productivity firms choose generic outsourcing to the North.

Keywords: input specificity, outsourcing, firm heterogeneity, incomplete contracts, hold-up problem

Codes JEL : F23, F12

\footnotetext{
${ }^{*}$ University of California - Berkeley.

$\dagger$ Auteur pour la correspondance : HEC Montréal, Department of International Business, 3000 Chemin de la Côte-Sainte-Catherine, Montréal (Québec), Canada H3T-2A7. Tél. : (514) 340-6043. Fax : (514) $340-6987$.

Courriel : ari.van-assche@hec.ca
} 


\section{Introduction}

Empirical studies have unveiled a systematic relationship between productivity and a firm's outsourcing strategy. In a study of Japanese manufacturing firms, Tomiura (2005a) found that only the most productive firms outsource internationally, while less productive firms outsource domestically. In a follow-up study, Tomiura (2005b) found that Japanese FDI firms are distinctively more productive than foreign outsourcing firms, which are equally productive as exporters and are clearly more productive than domestic firms.

To explain the relation between productivity and a firm's outsourcing strategy, recent theoretical studies have incorporated firm heterogeneity into international trade models. ${ }^{1}$ Antràs and Helpman (2004) map the property rights theory of Grossman and Hart (1986) and Hart and Moore (1990) into a general-equilibrium trade model with heterogeneous firms. In their model, two customized inputs are required to produce a final good: headquarter services that are provided by a Northern final good firm and manufacturing components that are supplied by an intermediate good firm located in the North or South. The authors find that in component-intensive industries, the assignment of property rights to the intermediate good firm (outsourcing) leads to higher variable profits than could be achieved by the assignment of property rights to the final good firm (vertical integration). If the fixed costs of outsourcing to the South is larger than outsourcing domestically, they find that the most productive firms outsource internationally, while the least productive firms outsource domestically. Grossman, Helpman and Szeidl (2005) use the Antràs-Helpman framework (2004) to assess the importance of firm heterogeneity in aggregate outsourcing patterns across countries. They predict that in component-intensive industries a reduction in the fixed cost of outsourcing leads to a positive correlation between outsourcing and foreign sourcing.

The existing studies have paid scant attention to the impact of input specificity on the organizational form that firms adopt (Helpman, 2005). Antràs and Helpman (2004) and Grossman, Helpman and Szeidl (2005) assume that inputs are completely specific, i.e. useless outside the existing relation. Counter to this assumption, however, the global value chain governance literature has argued that lead firms form different types of contracting arrangements with their suppliers depending on the degree of input

\footnotetext{
${ }^{1}$ This builds on a recent trade literature has analyzed the organization of international production by incorporating elements of incomplete contracts theory into generalequilibrium trade models. See Helpman (2005) and Spencer (2005) for comprehensive reviews of this literature.
} 
specificity. Sturgeon and Lee (2001) have identified three types of relations: (1) the captive supplier makes specific components using specialized machinery dedicated to a single lead firm's needs; (2) The turn-key supplier uses flexible manufacturing systems to produce customized components for multiple customers; (3) the commodity supplier provides generic components. According to Gereffi, Humphrey and Sturgeon (2005), the degree of input specificity adopted in a buyer-supplier relation not only depends on technological factors such as the complexity of transactions, but also on firm-specific characteristics such as the relative productivity of the lead firm and the supplier. ${ }^{2}$ Specifically, when the supplier has a relatively low productivity, then a contractual arrangement with a high degree of input specificity is chosen. When the supplier has a relatively high productivity, a contractual arrangement with a lower degree of input specificity is adopted.

This paper investigates the role of productivity on the optimal outsourcing strategy when final good firms can choose between the adoption of different types of inputs. For this purpose, we build on the Antràs-Helpman (2004) setting by allowing heterogeneous firms in an input-intensive industry to choose between the adoption of specific and generic inputs. ${ }^{3}$ In an incomplete contracting environment, this introduces an interesting tradeoff: even though specific inputs are more productive than generic inputs, final good producers might opt for generic inputs because it reduces the hold-up friction in the relationship by giving the intermediate good firm a positive ex post outside option. We demonstrate that the hold-up friction under generic outsourcing continuously rises with the final good firm's productivity level. If search costs are higher in the South than in the North, this implies that: (i) high productivity firms choose ideal outsourcing to the South, (ii) medium productivity firms choose generic outsourcing to the South, (iii) low productivity firms choose generic outsourcing to the North. This sorting pattern occurs despite the fact that fixed costs are assumed to be identical for all organizational forms.

The paper is organized as follows. Section 2 sets up the model. Section 3 describes the firms' optimization decisions and derives the hold-up friction under each organizational form. Section 4 then describes the equilibrium sorting of firms into different production structures and locations of production. Section 5 provides concluding remarks.

\footnotetext{
${ }^{2}$ Gereffi, Humphrey and Sturgeon (2005) use the term "competence" instead of productivity.

${ }^{3}$ Grossman and Helpman (2002), Nunn (2005) and Feenstra and Spencer (2005) also consider the impact of input specificity on the organization of international production. However, these models do not consider heterogeneous firms.
} 


\section{$2 \quad$ Model}

Consider a world with two countries - the North and the South - and a single industry that produces differentiated consumer goods. Global consumers spend a fraction $\mu$ of their aggregate income on the industry and have CES preferences for industry products:

$$
U=\left(\int_{0}^{n} y(i)^{\alpha} d i\right)^{\frac{1}{\alpha}},
$$

where $y(i)$ is the quantity demanded of final $\operatorname{good} i$ and $\alpha \in[0,1]$ is a parameter that determines the elasticity of demand. There are $n$ final good firms that each produce one final good variety $i$. Consumer preferences given by equation (1) lead to the following inverse demand function faced by the producer of good $y(i)$ :

$$
p(i)=A^{1-\alpha} y(i)^{-(1-\alpha)}, 0<\alpha<1,
$$

where $p$ is the price of the good and

$$
A=\frac{\mu}{\int_{0}^{n} p(i)^{\frac{-\alpha}{1-\alpha}} d i}
$$

is the aggregate consumption index. We treat the number of firms as a continuum, implying that firms take $A$ as given.

For the production of each final good variety, two parties are required: an intermediate good firm that produces the inputs and a final good firm that has the know-how (for example, technology, distributional or servicing network) to turn the input into a final good. We assume that only the North knows how to produce final goods, while inputs can be produced in both the North and the South. We also assume that intermediate good firms supply their inputs to at most one final good firm.

Similar to Melitz (2003), in our model, final good firms differ in productivity level. To learn his productivity, a final good firm incurs an irreversible fixed cost of entry equal to $F_{e}$ units of Northern labor. Upon paying this fixed cost, he learns his productivity level $\theta(i)$, which is randomly drawn from a known cumulative distribution $G(\theta)$. After observing his productivity level, the final good producer decides whether to start producing or remain idle. To initiate production, he needs to spend an additional fixed operating $\operatorname{cost} F$. This entails that final good firms below a certain threshold productivity level $\underline{\theta}$ remain idle. Final good $y(i)$ is produced with the production function

$$
y(i)=\theta(i) x(i),
$$


where $x(i)$ is the number of units of inputs. One unit of input $x(i)$ can be produced in the North $(N)$ and the South $(S)$ with one unit of labor. We assume that Southern wages $\omega^{S}$ are strictly lower than Northern wages $\omega^{N}$ and normalize the latter to 1: $\omega^{S}<\omega^{N}=1$. In addition, we assume that, regardless of the location of production, a fixed cost $f$ in units of Northern labor to start input production.

To start production, each final good firm forms a contract with one of a perfectly elastic supply of potential intermediate good firms in the North and the South. Ex ante contracts between the two parties are incomplete: only the allocation of residual rights and a lump-sum transfer between the two parties are ex ante contractible. The transfer is paid upon signing the contract. Since the two parties ex ante cannot sign an enforceable contract for the purchase of a specific quantity of inputs at a specific price, they bargain over the surplus from the relationship ex post, i.e. after the inputs have been produced. Following Grossman and Hart (1986) and Hart and Moore (1990), and similar to Antràs and Helpman (2004), we assume that ex post bargaining takes place under both ownership structures: vertical integration and outsourcing. We model this ex post bargaining as a Generalized Nash Bargaining game where intermediate good firms have a fixed bargaining share $\beta \in[0,1]$.

If a relationship breaks down during the ex post bargaining process, we assume that the contract becomes void and the ex ante transfer is returned. At that time, we assume that each party with residual rights can offer the original contract (including the original transfer) to a new partner. This will allow us to calculate the outside options.

Up to this point, our model replicates a simplified version of the AntràsHelpman (2004) framework where (i) industries are completely input-intensive and (ii) there are no differences in fixed costs between organizational forms. Under this scenario, Antràs-Helpman predict that all firms will outsource their production of inputs to intermediate good firms in the South. The intuition is straightforward: with such assumptions, the lower Southern wages make the South a strictly preferred location for input production. As we shall see below, our additional assumptions will permit us to get a richer and more realistic sorting pattern.

Final good firms ex ante make the technological choice between using ideal or generic inputs to produce final goods. ${ }^{4}$ An input is ideal for final good variety $y(i)$ if it is specifically tailored to the final good and worthless otherwise. A generic input can be used by any final good variety, but requires

\footnotetext{
${ }^{4}$ Ex post, final good firms cannot switch to a different type of input.
} 
the final good firm to spend additional customization costs $\rho$ per unit of input to make it compatible to final good specifications. This entails that generic inputs are less productive than ideal inputs. As we demonstrate below, final good firms thus face an interesting trade-off: on the one hand, ideal inputs are more productive than generic inputs. On the other hand, the adoption of generic inputs gives the intermediate good firm a positive $e x$ post outside option, thus reducing the hold-up problem. Specifically, if the ex ante contract breaks down at the time of the ex post Nash bargaining, the intermediate good firm can form a relationship with one of the idle final good firms and obtain fraction $\beta$ from the revenue generated in this new relationship. This presence of a positive ex post outside option increases the intermediate good firm's surplus share, thus increasing his incentive to supply inputs and reducing the hold-up problem.

To account for the stylized fact that search costs are higher across borders than within borders and that Southern firms have inferior search and communication technologies, we assume that only the Northern intermediate good firms are able to identify the threshold final good firm with productivity $\underline{\theta}$. This search cost difference implies that the intermediate good firm's ex post outside option differs under generic outsourcing to the North and South: while a Northern intermediate good firm in its ex post outside option can approach the threshold firm to form a new relation, a Southern intermediate good firm is forced to randomly sign up with any idle final good firm willing to enter in a relationship.

To summarize, active final good firms simultaneously choose three parameters ex ante: (i) the technological structure (i.e., whether to adopt ideal or generic inputs), (ii) the ownership structure (vertical integration or outsourcing), and (iii) the location of input production (North or South). We define production structure to comprise both a firm's technological and ownership structure. In particular, final good firms can choose from three feasible production structures: vertical integration $(I)$, ideal outsourcing $(O)$ and generic outsourcing $(G) .{ }^{5}$ We define organizational form $(k, l)$ to comprise a final good firm's production structure $k \in K=\{I, O, G\}$ and location of input production $l \in L=\{N, S\}$.

The model can be summarized by the following sequences of moves: (1) the final good firm decides whether it enters the market. If he enters, he incurs a fixed cost $F_{e}$ to have his productivity level $\theta(i)$ realized; (2) the

\footnotetext{
${ }^{5}$ Vertical integration with the adoption of generic inputs is never feasible: the hold-up problem is the same as under vertical integration with ideal inputs, and generic inputs are less productive than ideal inputs.
} 
final good firm decides if he wants to produce output or remain idle. If he decides to produce output, he chooses his organizational form $(k, l)$ by simultaneously choosing the production structure $k \in K=\{I, O, G\}$ and location of input production $l \in L=\{N, S\}$. In that case, the final good firm signs an incomplete contract with an intermediate good firm; (3) the intermediate good firm produces its inputs; (4) generalized Nash bargaining between the intermediate good firm and the final good firm. The final goods are then produced and sold, after which the proceeds are divided between the parties according to the outcome of generalized Nash bargaining.

\section{Hold-Up Friction}

We will solve the model through backward induction. To simplify notation, we from now on will drop the $i$ 's and refer to a firm's "ex post outside option" as its outside option. Under generalized Nash bargaining, each party receives the sum of its outside option plus its bargaining share of the quasi-rents. By quasi-rents we mean the surplus created in the relationship net of both parties' outside options. Let $V$ and $v$ denote the final good firm's and the intermediate good firm's outside options respectively; and $R$ the total revenue (or surplus) that the two parties can make from the sale of the final good. The final good firm thus obtains

$$
V_{k}^{l}+(1-\beta)\left(R_{k}^{l}-v_{k}^{l}-V_{k}^{l}\right)
$$

where $v_{k}^{l}, V_{k}^{l}$, and $R_{k}^{l}$ are functions of $x_{k}^{l}$ :

$$
v_{k}^{l}=v_{k}^{l}\left(x_{k}^{l}\right), V_{k}^{l}=V_{k}^{l}\left(x_{k}^{l}\right), \text { and } R_{k}^{l}=R_{k}^{l}\left(x_{k}^{l}\right) .
$$

The intermediate good firm obtains

$$
v_{k}^{l}+\beta\left(R_{k}^{l}-v_{k}^{l}-V_{k}^{l}\right)
$$

Prior to generalized Nash bargaining, the final good firm proposes the intermediate good firm a minimum lump-sum transfer $t$ that will guarantee the intermediate good firm's participation in the relationship. Since the supply of intermediate good firms is perfectly elastic, an intermediate good firm's participation constraint is nonnegative profits. The final good firm thus maximizes its profit function $\Pi_{k}^{l}$ :

$$
\max _{t} \Pi_{k}^{l}=V_{k}^{l}+(1-\beta)\left(R_{k}^{l}-v_{k}^{l}-V_{k}^{l}\right)-\rho_{k} x_{k}^{l}-F-t
$$


subject to the intermediate good firm's participation constraint of nonnegative profits $\pi_{k}^{l}$ :

$$
\pi_{k}^{l}=v_{k}^{l}+\beta\left(R_{k}^{l}-v_{k}^{l}-V_{k}^{l}\right)-\omega^{l} x_{k}^{l}-f+t \geq 0,
$$

where $\rho$ is the amount of resources that a final good firm spends to customize its inputs. It is strictly positive under generic outsourcing and zero for the other production structures:

$$
\rho_{G}>0 \text { and } \rho_{O}=\rho_{I}=0 .
$$

$F$ and $f$ denote fixed costs of starting production for final and intermediate good firms, respectively. We assume that these fixed costs are identical for all organizational forms.

By solving for the optimal lump-sum transfer $t$ and taking into account the intermediate good firm's profit-maximizing output level, the final good firm's optimal organizational form $\left(k^{*}, l^{*}\right)$ solves the following:

$$
\max _{k \in K, l \in L} \Pi_{k}^{l}=R\left(x_{k}^{l *}\right)-\left(\omega^{l}+\rho_{k}\right) x_{k}^{l *}-f-F,
$$

subject to:

$$
x_{k}^{l *}=\operatorname{argmax}_{x}\left\{v_{k}^{l}+\beta\left(R_{k}^{l}-v_{k}^{l}-V_{k}^{l}\right)-\omega^{l} x_{k}^{l}\right\} .
$$

To solve for the optimal organizational form, it is necessary to determine the intermediate good firm's and final good firm's outside options $v_{k}^{l}$ and $V_{k}^{l}$ under each organizational form $(k, l)$. We define a party's ex post outside option as the deviation payoff when a relationship breaks down, taking as given the continuance of all other relationships. Next, we summarize both parties' outside options under each organizational form.

I. Vertical Integration to the North or South. Following the property rights theory of the firm, we assume that under vertical integration to the North $(I, N)$ and South $(I, S)$, the final good producer has the residual rights over the inputs produced by the intermediate good firm. If a relationship breaks down, he therefore has the power to fire the intermediate good firm and seize a fraction $\delta$ of inputs. As a result, its outside option $V_{I}^{l}=\delta^{\alpha} R_{I}^{l}$. The intermediate good firm, however, has no outside option since it has no residual rights over the inputs it produces. As a result, $v_{I}^{l}=0$. Thus, for the organizational forms $(I, l)$, we have:

$$
V_{I}^{l}=\delta^{\alpha} R_{I}^{l} \text { and } v_{I}^{l}=0 .
$$


II. Ideal Outsourcing to the North or South. Under ideal outsourcing to the North $(O, N)$ and South $(O, S)$, the intermediate good firm nor the final good firm has an outside option since inputs are completely specialized and worthless otherwise. This implies that for the organizational forms $(O, l)$ we have:

$$
v_{O}^{l}=V_{O}^{l}=0
$$

III. Generic Outsourcing to the North. Under generic outsourcing to the North $(G, N)$, generic inputs can be used by all final good firms that have chosen to adopt generic inputs. In that case, the final good firm in Nash equilibrium does not have an outside option since all other intermediate good firms that have entered the market are already tied up in a relation with other final good firms. Thus, $V_{G}^{N}=0$. The intermediate good firm, however, can offer the generic inputs $x$ that it has produced for the original relationship to the idle threshold final good firm with productivity level $\underline{\theta}$ for a share $\beta$ of total revenue $\underline{R}$ generated in this new relationship. ${ }^{6}$ As is shown in Appendix A, the intermediate good firm's Nash equilibrium outside option under $(G, N)$ is a constant fraction of the revenue that could have been generated in the original relation:

$$
v_{G}^{N}=\beta\left(\frac{\theta}{\underline{\theta}}\right)^{-\alpha} R_{G}^{N}
$$

where the fraction is increasing in the intermediate good firm's bargaining share $\beta$, and decreasing in the final good firm's productivity level relative to the threshold firm $\theta / \underline{\theta}$ and the elasticity of substitution. Thus, for the organizational form $(G, N)$, we have:

$$
V_{G}^{N}=0 \text { and } v_{G}^{N}=\beta\left(\frac{\theta}{\underline{\theta}}\right)^{-\alpha} R_{G}^{N}
$$

IV. Generic Outsourcing to the South. Similar to generic outsourcing to the North, the final good firm under generic outsourcing to the South $(G, S)$ in Nash equilibrium does not have an outside option: $V_{G}^{N}=0$. An intermediate good firm, however, can randomly sign up with any idle final good firm willing to enter in a relationship in the event of a breakdown of the original relationship. Let $\theta_{0}$ denote the lowest productivity level of such

\footnotetext{
${ }^{6}$ The assumption that the intermediate good firm receives share $\beta$ of total revenue in the outside relationship is equivalent to assuming that he can only deviate once.
} 
firms. In that case, the expected productivity level of the final good firm with whom he ends up is:

$$
\xi=\int_{\theta_{0}}^{\underline{\theta}} \theta G(\theta) d \theta<\underline{\theta} .
$$

This leaves the Southern intermediate good firm with the following outside option:

$$
v_{G}^{S}=\beta\left(\frac{\theta}{\xi}\right)^{-\alpha} R_{G}^{S} .
$$

A comparison of (10) and (12) shows that, all else equal, the intermediate good firm's outside option under generic outsourcing to the South is weakly lower than under generic outsourcing to the North. Thus, for the organizational form $(G, S)$ we have:

$$
V_{I}^{l}=0 \text { and } v_{G}^{S}=\beta\left(\frac{\theta}{\xi}\right)^{-\alpha} R_{G}^{S} .
$$

We can use the outside options to calculate the degree of input specificity for each organizational form. Nunn (2005) defines an input to be specific if its value within a buyer-seller relationship is significantly higher than outside the relationship. Thus, we define the degree of input specificity $d_{k}^{l}$ as the difference between the total revenue that can be created with an input within a buyer-seller relationship and the total revenue that can be created with that input in the outside option as a share of total revenue within the buyer-seller relationship. In our notation:

$$
d_{k}^{l}=\frac{\left(R_{k}^{l}-v_{k}^{l} / \beta\right)}{R_{k}^{l}} .
$$

If $d_{k}^{l}=0$, then there is no input specificity since the inputs are equally valuable within and outside the buyer-seller relationship. If $d_{k}^{l}=1$, then there is complete input specificity since inputs are worthless in the outside relationship. Using the outside options $v_{k}^{l}$, we can calculate the degree of input specificity for each organizational form:

$$
d_{k}^{l}=\left\{\begin{array}{ccc}
1 & \text { if } & (I, l) \\
1 & \text { if } & (O, l) \\
1-\left(\frac{\theta}{\xi}\right)^{-\alpha} & \text { if } & (G, S) \\
1-\left(\frac{\theta}{\underline{\theta}}\right)^{-\alpha} & \text { if } & (G, N)
\end{array}\right.
$$


Figure 1 depicts the degree of input specificity and final good productivity for the various organizational forms that the final good firm can adopt. The variable $d_{k}^{l}$ is measured along the vertical axis and $\theta / \underline{\theta}$ is measured along the horizontal axis.

\section{[Figure 1 about here]}

As is demonstrated in Figure 1, the degree of input specificity depends on the organizational form adopted and on the final good firm's productivity level. Specifically:

Lemma 1 For any productivity $\theta$ of a final good firm, we have:

$$
d_{G}^{N} \leq d_{G}^{S}<d_{O}^{l}=d_{I}^{l}=1
$$

Under generic outsourcing to the North and South, the degree of input specificity $d_{G}^{l}$ is an increasing and concave function of the final good firm's productivity $\theta$ and equals to 1 in the limit of $\theta$ equals $\infty$.

For a given final good firm productivity $\theta$, inputs are completely specific under vertical integration and ideal outsourcing since the intermediate good firm has no outside option. The degree of input specificity under generic outsourcing to the North and South, however, is less than 1 because under these two organizational forms intermediate good firms have strictly positive outside options. Comparing equations (10) and (12), the degree of input specificity under generic outsourcing to the South is higher than under generic outsourcing to the North. This is because the expected outside option under generic outsourcing to the South is lower than the outside option under generic outsourcing to the North. Finally, from equation (14), the degree of input specificity under generic outsourcing to the North and South is an increasing and concave function of the final good firm's productivity and approaches 1 as final good productivity $\theta$ goes to infinity.

Inserting equations (8), (9), (11) and (13) into equation (7) permits us to rewrite the final good firm optimization as:

$$
\max _{k \in K, l \in L} \Pi_{k}^{l}=R\left(x_{k}^{l *}\right)-\left(\omega^{l}+\rho_{k}\right) x_{k}^{l *}-f-F
$$

subject to

$$
x_{k}^{l *}=\operatorname{argmax}_{x}\left\{s_{k}^{l} R_{k}^{l}-\omega^{l} x_{k}^{l}\right\},
$$


where the intermediate good firm's ex post surplus share

$$
s_{k}^{l}=\left\{\begin{array}{cll}
\beta\left(1-\delta^{\alpha}\right) & \text { if } & (I, l) \\
\beta\left(1+(1-\beta)\left(1-d_{l}^{k}\right)\right) & \text { if } & (O, l) \text { or }(G, l) .
\end{array}\right.
$$

Figure 2 uses equations (14) and (17) to depict the intermediate good firm's ex post surplus share for the various organizational forms.

[Figure 2 about here]

As is demonstrated in Figure 2, the intermediate good firm's ex post surplus share is a function of the ownership structure and the degree of input specificity. First, the intermediate good firm's ex post surplus share is unambiguously smaller under vertical integration than under the outsourcing because the final good firm has a positive outside option while the intermediate good firm has no outside option (see equation (8)). Second, the intermediate good firm's ex post surplus share under outsourcing linearly decreases with the degree of input specificity. Combining equation (17) with lemma 1, we can thus infer that the intermediate good firm's ex post surplus share under outsourcing is higher under generic outsourcing to the North than under generic outsourcing to the South and ideal outsourcing, in that order. From equations (14) and (17), the intermediate good firm's ex post surplus share under generic outsourcing to the North and South is a negative and convex function of its partner's productivity level. As its partner's productivity level increases, its ex post surplus share approaches that of under ideal outsourcing $\beta$. Indeed, the intermediate good firm's $e x$ post surplus share gap between generic outsourcing to the North, generic outsourcing to the South and ideal outsourcing in the limit of $\theta$ approaching infinity becomes negligible.

The severity of the hold-up friction for each firm under each organizational form can be determined by comparing with a complete contracting environment. In such a case, the two parties would bargain over the division of the revenue upon signing the contract and there would be no renegotiation ex post. Using (7), it is straightforward to show that the final good firm under complete contracts chooses to adopt ideal inputs and agrees to give the intermediate good firm the entire revenue created by the relationship $\left(s^{*}=1\right){ }^{7}$ In our model, we can thus capture the hold-up friction with

\footnotetext{
${ }^{7}$ This outcome provides a nonnegative profit to the final good firm since he extracts the entire profit of the relationship via the lump-sum transfer $t$.
} 
$1-s_{k}^{l}$. In Figure 3, we use equation (17) to depict the hold-up friction for all organizational forms.

\section{[Figure 3 about here]}

Figure 3 illustrates that the hold-up friction depends on (i) the ownership structure and (ii) the degree of input specificity. This permits us to formulate the following proposition:

Proposition 1 For a given productivity $\theta$, the hold-up friction increases as we go from generic outsourcing to the North, to generic outsourcing to the South, to ideal outsourcing, and to vertical integration, in that order. Under generic outsourcing to the North and South, the hold-up friction is a positive and concave function of the final good firm's productivity $\theta$. In the limit of $\theta \longrightarrow \infty$, the hold-up friction under generic outsourcing to the North and South becomes equal to that under ideal outsourcing.

Proof. Follows from combining the definition of hold-up friction as $1-s_{k}^{l}$, equations (14) and (17).

\section{Organizational Forms}

In this section, we analyze the final good firm's optimal choice of organizational form and show that, in equilibrium, this choice of the final good firm depends on its productivity. By solving the intermediate good firm's optimization problem given by equation (16) and inserting $x_{k}^{l *}$ and the corresponding price level $p_{k}^{l *}$ into equation (15), the final good firm's profit maximization problem can be rewritten as:

$$
\max _{k \in K, l \in L} \Pi_{k}^{l}\left(\theta^{\frac{\alpha}{1-\alpha}}\right)=A \theta^{\frac{\alpha}{1-\alpha}} Z_{k}^{l}-f-F
$$

where

$$
Z_{k}^{l}=\left(1-\alpha s_{k}^{l}\right)\left(\frac{\alpha s_{k}^{l}}{\omega^{l}\left(1+\rho_{k}\right)}\right)^{\frac{\alpha}{1-\alpha}} .
$$

From equations (18) and (19), the choice of organizational form not only depends on the ensuing hold-up friction $1-s_{k}^{l}$, but also on other cost differences between organizational forms. ${ }^{8}$ Specifically, final good firms also

\footnotetext{
${ }^{8}$ Antràs and Helpman (2004) show that the real consumption index $A$ can be implicitly derived from the free-entry condition $\int_{\theta}^{\infty} \Pi(\theta, A) d G(\theta)=F_{e}$. Then, one can use $A$ to derive implicit solutions for the remaining values $\underline{\theta}, \theta_{1}, \theta_{2}$ and $\theta_{3}$.
} 
need to take into account the differences in wages $w^{l}$ between the North and the South and differences in customization costs $\rho_{k}$ between the adoption of ideal and generic inputs.

In Appendix B, we derive a final good firm's profit as a function of its productivity for all feasible organizational forms. This permits us to describe how firms' sorting into different organizational forms depends on productivity $\theta$. Let $\theta_{1}, \theta_{2}$ and $\theta_{3}$ denote the productivity level for which $\Pi_{G}^{N}=\Pi_{G}^{S}, \Pi_{G}^{S}=\Pi_{O}^{S}$ and $\Pi_{G}^{N}=\Pi_{O}^{S}$, respectively. We can then formulate the following theorem:

Theorem 1 In completely input-intensive industries, four scenarios can occur:

1. If $\rho$ is large, the optimal organizational form for all final good firms is ideal outsourcing to the South.

2. If $\rho$ and $w^{S}$ are small, then generic outsourcing to the South is optimal for final good firms with $\theta \in\left[\underline{\theta}, \theta_{2}\right]$ and ideal outsourcing to the South is optimal for final good firms with $\theta \in\left[\theta_{2}, \infty\right]$.

3. If $\rho$ is small and $w^{S}$ is large, then generic outsourcing to the North is optimal for final good firms with $\theta \in\left[\underline{\theta}, \theta_{3}\right]$ and ideal outsourcing to the South is optimal for final good firms with $\theta \in\left[\theta_{3}, \infty\right]$.

4. If $\rho$ is small and $w^{S}$ takes on an intermediate value, then generic outsourcing to the North is optimal for final good firms with $\theta \in\left[\underline{\theta}, \theta_{1}\right]$; generic outsourcing to the South is optimal for final good firms with $\theta \in\left[\theta_{1}, \theta_{2}\right]$; and ideal outsourcing is optimal for final good firms with $\theta \in\left[\theta_{2}, \infty\right]$.

Proof. See Appendix B.

In the proof of Theorem 1, we demonstrate that vertical integration to the North $(I, N)$, vertical integration to the South $(I, S)$ and and ideal outsourcing to the North $(O, N)$ are not feasible organizational forms. We also show that, under ideal outsourcing to the South $(O, S)$, the profit function $\Pi_{O}^{S}$ is a positive and linear function of $\theta^{\frac{\alpha}{1-\alpha}}$. Under generic outsourcing to the North $(G, N)$ and South $(G, S)$, however, the profit functions $\Pi_{G}^{l}$ are increasing and concave functions in $\theta^{\frac{\alpha}{1-\alpha}}$. Furthermore, in the limit of $\theta \longrightarrow 0$, $\Pi_{G}^{N \prime}$ and $\Pi_{G}^{S \prime}$ exceed $\Pi_{O}^{S \prime}$, while in the limit of $\theta \longrightarrow \infty, \Pi_{G}^{N \prime}<\Pi_{G}^{S \prime}<\Pi_{O}^{S}$. These well-behaved characteristics of the profit functions allow us to graphically analyze the sorting pattern of firms depending on their productivity level and the parameter values of $w^{S}$ and $\rho$. 
To provide the logic behind Theorem 1, we graphically depict in Figure 4 the scenario in which the most organizational forms coexist: scenario 4 . The other scenarios are derived and interpreted in Appendix B.

\section{[Figure 4 about here]}

As is depicted in figure 4, a firm's optimal organizational form depends on its productivity $\theta$. Specifically, when $\rho$ and $w^{s}$ take on medium values, the following sorting pattern occurs: (i) low productivity firms choose generic outsourcing to the North, (ii) medium productivity firms choose generic outsourcing to the South, and (iii) high productivity firms choose ideal outsourcing to the South. The intuition is the following: low productivity firms $\left(\underline{\theta} \leq \theta \leq \theta_{1}\right)$ choose generic outsourcing to the North $(G, N)$ because the ensuing low hold-up friction $1-s_{G}^{N}$ outweighs both the higher wages of producing inputs in the North and the customization costs $\rho$ of using generic inputs. As the final good firm's productivity increases, however, the hold-up friction rises more rapidly under generic outsourcing to the North than the other organizational forms (see Figure 2). For medium productivity firms with $\theta_{1} \leq \theta \leq \theta_{2}$, the benefit of lower wages in the South thus outweighs the lower hold-up friction of generic outsourcing to the North. As a result, medium productivity firms opt for generic outsourcing to the South $(G, S)$. Finally, for high productivity firms with $\theta \geq \theta_{2}$, the cost of paying customization costs exceeds the benefit of a lower hold-up friction that generic outsourcing to the South entails. As a result, high productivity firms choose ideal outsourcing to the South $(O, S)$.

Scenario's 3 and 4 of Theorem 1 are consistent with the empirical evidence that only the most productive firms internationalize, while the least productive firms source their inputs domestically. Unlike Antràs and Helpman (2004) and Grossman, Helpman and Szeidl (2004), however, our model does not rely on the assumption that the fixed organizational costs are higher when the intermediate good firm is located in the South than the North to obtain this result. In particular, we assume that fixed costs are identical for all organizational forms. We thus state the following corollary:

Corollary 1 In input-intensive industries, only the most productive final good firms internationalize since the increase in hold-up friction related to internationalization is least severe for them.

We can use Figure 3 to provide the intuition behind Corollary 1. In Figure 3 , the difference in hold-up friction between generic outsourcing to the 
North $(G, N)$ and generic outsourcing to the South $(G, S)$ is smaller for high productivity firms than it is for low productivity firms. This implies that the increase in hold-up friction related to internationalization is less severe for high productivity firms than low productivity firms. As a result, high productivity firms internationalize, while low productivity firms source domestically. Corollary 1 thus identifies a new theoretical reason why only the most productive firms internationalize.

Scenario's 2, 3 and 4 of Theorem 1 provide insights into which type of firms are most likely to adopt generic inputs:

Corollary 2 In completely input-intensive industries, high productivity final good firms adopt ideal inputs, while low productivity final good firms adopt generic inputs.

We can use Figure 3 and Proposition 1 to provide the intuition behind Corollary 2. In Figure 3, the difference in hold-up friction between generic outsourcing to the South $(G, S)$ and ideal outsourcing to the South $(I, S)$ is smaller for high productivity firms than low productivity firms. This implies that the benefit for high productivity firms of adopting generic inputs is smaller than for low productivity firms. As a result, high productivity firms adopt ideal inputs, while low productivity firms adopt generic inputs.

Corollary 2 is consistent with Gereffi, Humphrey and Sturgeon's (2005) notion that the relative productivity of lead firms and suppliers is an important determinant of the organizational form adopted: when the relative productivity of the final good firm versus the intermediate good firm is high, then ideal inputs are adopted. When the relative productivity of the final good firm versus the intermediate good firm is low, generic inputs are adopted.

\section{Conclusion}

This paper has addressed the role of productivity on a firm's optimal outsourcing strategy. For this purpose, we expand the Antràs-Helpman (2004) model by allowing heterogeneous final good firms to choose between the adoption of ideal and generic inputs. This introduces an interesting tradeoff: while specific inputs are more productive than generic inputs, final good producers might opt for generic outsourcing since it reduces the severity of the hold-up friction under generic outsourcing. We demonstrate that the hold-up friction under generic outsourcing is larger for high productivity firms than for low productivity firms. This implies that the final good firms' 
sorting into different organizational forms depends on their productivity. We show that if search frictions are larger in the South than the North, this implies that the highest productivity firms choose ideal outsourcing to the South, while medium productivity firms choose generic outsourcing to the South, and low productivity firms choose generic outsourcing to the North.

Our result is consistent with Antràs and Helpman's (2004) prediction and Tomiura's (2005a, 2005b) empirical evidence that only the most productive firms outsource internationally. However, our result does not rely on the assumption that the fixed cost of outsourcing to the South is larger than that of outsourcing to the North. Our model thus provides a new explanation why only the most productive firms choose to internationalize: given that the hold-up friction under generic outsourcing is an increasing function of the final good firm's productivity level, the cost in terms of hold-up friction of shifting input production to the South is least severe for high productivity firms.

Our model also provides novel insights into the determinants of the type of outsourcing relationship that firms have with their suppliers. Consistent with Gereffi, Humphrey and Sturgeon's (2005) notion that the relative productivity of a lead firm versus a supplier is an important determinant of the organizational choice, we find that only the least productive firms adopt generic inputs, while the most productive firms adopt ideal inputs.

In this paper, we focused on completely input-intensive industries where the final good firm does not conduct relationship-specific investments. An interesting extension of the model would be to introduce the choice between ideal and generic inputs into a framework where both parties conduct relationship-specific inputs. This would allow us to co-determine heterogeneous firms' technological structure, ownership structure and location of production. 


\section{Appendix A: Derivation of equation (10)}

In the calculation of the intermediate good firm's ex post outside option under generic outsourcing to the North, we assume that the intermediate good firm carries over the original contract to the outside relation. As a result, the intermediate good firm provides the same transfer $t$ to the threshold firm as specified in the original contract. Furthermore, we assume that none of both parties have an outside option in the outside relation. The derivation has two steps. First, we derive the intermediate good firm's surplus share. Second, we demonstrate that the threshold firm will always end up with nonnegative profits.

Step 1. Let $x$ denote the amount of inputs that the intermediate good firm has produced for the original relationship. Then, from equation (3), the threshold firm (with productivity $\underline{\theta}$ ) will be able to produce:

$$
\underline{y}=\underline{\theta} x .
$$

From equation (2), the corresponding output price will be:

$$
\underline{\mathrm{p}}=A^{1-\alpha}(\underline{\theta} x)^{-(1-\alpha)} .
$$

If the threshold firm agrees to proceed, the intermediate good firm will obtain surplus share $\beta \underline{\mathrm{R}}$ from this relationship, while the threshold final good firm obtains $(1-\beta) \underline{R} .{ }^{9}$ Using equations (A-1) and (A-2), the intermediate good firm's outside option equals:

$$
v=\beta A^{1-\alpha}(\underline{\theta} x)^{\alpha} .
$$

Using equations (2) and (3), we derive the revenue that could have been created in the inside (original) relationship:

$$
R=A^{1-\alpha}(\theta x)^{\alpha}
$$

The aggregate consumption index $A$ is identical for all final good firms. By using equation (A-4) to solve for $A$ and inserting it into (A-3), we can express $v$ as a function of $R$ :

$$
v_{G}^{N}=\beta\left(\frac{\theta}{\underline{\theta}}\right)^{-\alpha} R_{G}^{N}
$$

\footnotetext{
${ }^{9}$ Both parties face zero outside options.
} 
From equation (A-5), the intermediate good firm's ex post outside option is a constant fraction of the revenue that could have been generated in the original relation.

Step 2. From equation (4), the threshold final good firm will only agree to enter the market if its profits are nonnegative:

$$
\underline{\pi}=(1-\beta) A^{1-\alpha}\left(\underline{\theta} x_{G}^{N}\right)^{\alpha}-\rho x_{G}^{N}-F-t \geq 0 .
$$

To prove that this is the case, we need to first solve for the entire model. Once we have done so, we can solve for the optimal $t^{*}$ and $x^{*}$ in the original relationship. Next, we can use the characteristics of the threshold firm to solve for $A$. By combining these calculations, we can demonstrate that the threshold firm's profits are always nonnegative.

1. The intermediate good firm carries over the contract from the original relationship. As a result, he is required to transfer to the threshold firm the same amount $t$ that he would have transferred in the original relationship. From equation (5), it can be derived that in the original relationship:

$$
-t^{*}=s_{G}^{N} R\left(x_{G}^{N}\right)-x_{G}^{N}-f .
$$

2. From equation (16), it can be derived that the intermediate good firm produces the following amount of inputs for the original relationship:

$$
x_{G}^{N *}=A\left(\alpha s_{G}^{N} \theta^{\alpha}\right)^{\frac{1}{1-\alpha}} .
$$

3. To solve for $A$, we first notice from Theorem 1 that when generic outsourcing to the North is chosen by at least one final good firm, then the least productive active final good firm chooses generic outsourcing to the North. This implies that — if at least one final good firm chooses generic outsourcing to the North - the threshold firm's profitmaximizing original form is generic outsourcing to the North. Using equations (14) and (17), the threshold firm would have had a surplus share of $1-\beta(2-\beta)$ if he would have chosen to be active. Using (16), he would have had the following amount of inputs at its disposal:

$$
\underline{x}^{*}=A\left(\alpha \beta(2-\beta) \underline{\theta}^{\alpha}\right)^{\frac{1}{1-\alpha}} .
$$

The special characteristic of the threshold firm is that he initially is indifferent between being active in the market and remaining idle. This 
implies that with $\underline{x}^{*}$ at his disposal, he would have faced zero profits. From equation (6), this implies that:

$$
A^{1-\alpha}\left(\underline{\theta} \underline{x}^{*}\right)^{\alpha}-(1+\rho) \underline{x}^{*}-f-F=0 .
$$

By inserting equation (A-9) into equation (A-10), we can thus derive A:

$$
A=\frac{f+F}{(\alpha \beta(2-\beta) \underline{\theta})^{\frac{\alpha}{1-\alpha}}(1-(1+\rho) \alpha \beta(2-\beta))} .
$$

We now have all the required information to calculate whether the threshold firm in the outside relationship faces nonnegative profits. By inserting equations (A-7), (A-8) and (A-11) into (A-6) and rearranging, the threshold firm has a nonnegative profit if the following condition holds:

$$
\left(\frac{s_{G}^{N} \theta}{\beta(2-\beta)}\right)^{\frac{\alpha}{1-\alpha}}\left(\frac{(1-\beta)(\theta / \underline{\theta})^{\alpha}+s_{G}^{N}-(1+\rho) \alpha s_{G}^{N}}{1-(1+\rho) \alpha \beta(2-\beta)}\right) \geq 1 .
$$

This is always the case since both terms within brackets are larger than 1 . We can conclude that the threshold firm is always willing to take over the original contract with the intermediate good firm. 


\section{Appendix B: Proof of Theorem 1}

In this appendix, we will first demonstrate that vertical integration $(I, l)$ and ideal outsourcing to the North $(O, N)$ are never optimal strategies. Next, we will analyze the characteristics of the profit functions under the remaining organizational forms. This will allow us to prove Theorem 1.

Elimination of $(I, S),(I, N)$ and $(\boldsymbol{O}, \boldsymbol{N})$. Vertical integration to the North $(I, N)$, vertical integration to the South $(I, S)$ and ideal outsourcing to the North $(O, N)$ are never optimal strategies because they are dominated by ideal outsourcing to the South $(O, S)$. We can demonstrate this by comparing the differences in wages $w^{l}$ and hold-up friction $1-s_{k}^{l}$ between these organizational forms. We do not need to consider customization costs $\rho_{k}$ since firms under all these organizational forms adopt ideal inputs.

1. Ceteris paribus, $(O, S)$ dominates $(O, N)$ since firms face the same hold-up friction, while wages in the South are lower than in the North.

2. Ceteris paribus, $(O, S)$ dominates $(I, N)$ since the hold-up friction and wages are lower under $(O, S)$ than $(I, N)$.

3. Ceteris paribus, $(O, S)$ dominates $(I, S)$ since the hold-up friction are lower under $(O, S)$ than $(I, N)$ and wages are the same.

This implies that $(I, N),(I, S)$ and $(O, N)$ are never optimal strategies.

For the remaining organizational forms $(G, N),(G, S)$ and $(O, S)$, we need to analyze the characteristics of their profit functions $\Pi_{k}^{l}\left(\theta^{\frac{\alpha}{1-\alpha}}\right)$. We will first analyze the first and second order conditions of the three profit functions.

Ideal Outsourcing to the South. From equations (18) and (19), the final good firm's profit function $\Pi_{O}^{S}$ linearly increases in $\theta^{\frac{\alpha}{1-\alpha}}$ :

$$
\Pi_{O}^{S \prime}=A\left(\frac{\alpha \beta}{\omega^{S}}\right)^{\frac{\alpha}{1-\alpha}}\left(1-\alpha+\alpha \beta\left(\frac{1-\beta}{\beta}\right)\right)>0 .
$$

and

$$
\Pi_{O}^{S \prime \prime}=0
$$

Generic Outsourcing to the North and South. From equations (18) and (19), the final good firms' profit functions $\Pi_{G}^{N}$ and $\Pi_{G}^{S}$ are increasing 
and concave functions of $\theta^{\frac{\alpha}{1-\alpha}}$ :

$$
\Pi_{G}^{l \prime}=A\left(\frac{\alpha s_{G}^{l}}{\omega^{l}\left(1+\rho_{G}\right)}\right)^{\frac{\alpha}{1-\alpha}}\left(1-\alpha+\alpha \beta\left(\frac{1-s_{G}^{l}}{s_{G}^{l}}\right)\right)>0
$$

and

$\Pi_{G}^{l \prime \prime}=-A\left(\frac{\alpha s_{G}^{l}}{\omega^{l}\left(1+\rho_{G}\right)}\right)^{\frac{\alpha}{1-\alpha}} \frac{\alpha\left(s_{G}^{l}-\beta\right)}{s_{G}^{l 2} \theta^{\frac{\alpha}{1-\alpha}}}\left((1-\alpha)\left(s_{G}^{l}-\beta\right)+\alpha \beta\left(1-s_{G}^{l}\right)\right) \leq 0$.

To ensure that each organizational form is feasible, we also need to analyze the profit functions in their limits. In the limit of $\theta \longrightarrow 0$, the slopes of the profit functions under $(G, N)$ and $(G, S)$ approaches infinity:

$$
\lim _{\theta \longrightarrow 0} \Pi_{G}^{l \prime}=+\infty
$$

The slope of the profit function under $(O, S)$ is given by equation (B-1). A comparison of equations (B-3) and (B-1) demonstrates that for low productivity levels:

$$
\Pi_{G}^{N \prime}>\Pi_{O}^{S \prime} \text { and } \Pi_{G}^{S \prime}>\Pi_{O}^{S \prime}
$$

Next, we need to determine for which productivity $\theta,(G, N)$ dominates $(G, S)$. Let $\theta_{1}$ denote the productivity level where $\Pi_{G}^{S}=\Pi_{G}^{N}$. Using equations (14), (17) and (B-2), $\Pi_{G}^{N \prime}>\Pi_{G}^{S \prime}$ for $\theta<\theta_{1}$ as long as $w^{S}$ is not too small. $\Pi_{G}^{N \prime}<\Pi_{G}^{S \prime}$ otherwise. Combining these results with (B-4) and the characteristics of the profit functions, the following ranking of profit functions holds if $w^{S}$ is not too small and $\theta$ is close to zero:

$$
\Pi_{G}^{N} \geq \Pi_{G}^{S} \geq \Pi_{O}^{S}
$$

In the limit of $\theta \longrightarrow \infty$, the slope of the profit functions under $(G, N)$ and $(G, S)$ is:

$$
\lim _{\theta \longrightarrow \infty} \Pi_{G}^{l \prime}=A\left(\frac{\alpha \beta}{\left(1+\rho_{G}\right) \omega^{l}}\right)^{\frac{\alpha}{1-\alpha}}\left(1-\alpha+\alpha \beta\left(\frac{1-\beta}{\beta}\right)\right)
$$

A comparison of equations (B-1) and (B-6) allows us to rank the slopes of the profit functions as $\theta$ approaches infinity: $\Pi_{G}^{N \prime}<\Pi_{G}^{S \prime}<\Pi_{O}^{S}$. This is because $\rho$ is strictly positive under $(G, l)$ and zero under $(O, S)$. In addition, wages are lower in the South than in the North. From the characteristics of the profit functions, this implies that for a sufficiently high productivity:

$$
\Pi_{G}^{N} \leq \Pi_{G}^{S} \leq \Pi_{O}^{S}
$$


These well-behaved characteristics of the profit functions allow us to graphically analyze the sorting pattern of firms depending on the parameter values of $w^{S}$ and $\rho$. In Figure 4, we depict as a benchmark scenario the scenario in which all three organizational forms are represented. We can use this graphical representation to distinguish four scenarios:

Scenario 1. When $\rho$ is sufficiently large, generic outsourcing to the North and South are not feasible strategies. From equations (B-1) and (B-2), an increase in $\rho$ reduces the slopes of $\Pi_{G}^{S}$ and $\Pi_{G}^{N}$, while leaving $\Pi_{O}^{S}$ unchanged. If the slopes of $\Pi_{G}^{S}$ and $\Pi_{G}^{N}$ are sufficiently small, then both profit functions will intersect with $\Pi_{O}^{S}$ at $\theta<\underline{\theta}$. In that case, only ideal outsourcing to the South is a feasible strategy.

Scenario 2. When $\rho$ is not too large and $w^{s}$ is sufficiently small, generic outsourcing to the North is not a feasible strategy. From equations (B-1) and (B-2), a decrease in $w^{S}$ increases the slopes of $\Pi_{G}^{S}$ and $\Pi_{O}^{S}$, while leaving the slope of $\Pi_{G}^{N}$ unchanged. If the slopes of $\Pi_{G}^{S}$ and $\Pi_{O}^{S}$ increase sufficiently, then $\Pi_{G}^{N}$ intersects with $\Pi_{G}^{S}$ at $\theta<\underline{\theta}$. Generic outsourcing to the North thus is not a feasible strategy. In that case, the following sorting pattern occurs: generic outsourcing to the South is optimal for final good firms with $\theta \in\left[\underline{\theta}, \theta_{2}\right]$ and ideal outsourcing to the South is optimal for final good firms with $\theta \in\left[\theta_{2}, \infty\right]$.

Scenario 3. When $\rho$ is not too large and $w^{S}$ is sufficiently large, then generic outsourcing to the South is not a feasible strategy. An increase in $w^{S}$ reduces the slopes of $\Pi_{G}^{S}$ and $\Pi_{O}^{S}$, while the slope of $\Pi_{G}^{N}$ remains unchanged. If the slopes of $\Pi_{G}^{S}$ and $\Pi_{O}^{S}$ decrease sufficiently, then $\Pi_{G}^{N}$ intersects with $\Pi_{O}^{S}$ before $\Pi_{G}^{N}$ intersects with $\Pi_{G}^{S}$. Generic outsourcing to the South thus is not a feasible strategy. In that case, the following sorting pattern occurs: generic outsourcing to the North is optimal for final good firms with $\theta \in\left[\underline{\theta}, \theta_{3}\right]$ and ideal outsourcing to the South is optimal for final good firms with $\theta \in\left[\theta_{3}, \infty\right]$.

Scenario 4. If $\rho$ and $w^{s}$ take on medium values, all organizational forms are represented. In that case, the following sorting pattern occurs (see Figure 4): generic outsourcing to the North is optimal for final good firms with $\theta \in\left[\underline{\theta}, \theta_{1}\right]$; generic outsourcing to the South is optimal for final good firms with $\theta \in\left[\theta_{1}, \theta_{2}\right]$; and ideal outsourcing is optimal for final good firms with $\theta \in\left[\theta_{2}, \infty\right]$. 


\section{References}

[1] Antràs, P., Helpman, E., 2004. Global Sourcing. Journal of Political Economy 112, 552-580.

[2] Feenstra, R.C., Spencer, B.J., 2005. Contractual versus Generic Outsourcing: The Role of Proximity. National Bureau of Economic Research Working Paper No. 11885.

[3] Grossman, G., Helpman, E., 2002. Integration versus Outsourcing in Industry Equilibrium. Quarterly Journal of Economics. 117, 85-120.

[4] Grossman, G., Helpman, E., Szeidl, A., 2004. Complementarities between Outsourcing and Foreign Sourcing, mimeo.

[5] Gereffi, G., Humphrey, J., Sturgeon, T., 2005. The Governance of Global Value Chains. Review of International Political Economy 12, $78-104$.

[6] Grossman, S.J., Hart, O.D., 1986. Costs and Benefits of Ownership: A Theory of Vertical and Lateral Integration. Journal of Political Economy 94, 691-719.

[7] Hart, O.D., Moore, J., 1990. Property Rights and the Nature of the Firm. Journal of Political Economy 98, 1119-1158.

[8] Helpman, E., 2005. Trade, FDI, and the Organization of Firms. mimeo.

[9] Melitz, M.J., 2003. The Impact of Trade on Intra-Industry Reallocations and Aggregate Industry Productivity. Econometrica 71, 16951725 .

[10] Nunn, N., 2005. Relationship Specificity, Incomplete Contracts and the Pattern of Trade. Mimeo.

[11] Spencer, B.J., 2005. International Outsourcing and Incomplete Contracts. Canadian Journal of Economics 38, 1107-1135.

[12] Sturgeon, T.J., Lee, J.-R., 2001. Industry Co-evolution and the Rise of Shared Supply-Base for Electronics Manufacturing. MIT Industrial Performance Center Globalization Study Working Paper No. 01-002.

[13] Tomiura, E., 2005a. Foreign Outsourcing and Firm-Level Characteristics: Evidence from Japanese Manufacturers. Journal of the Japanese and International Economies, 19, 255-271. 
[14] Tomiura, E., 2005b. Foreign Outsourcing, Exporting, and FDI: A Productivity Comparison at the Firm Level. Mimeo. 


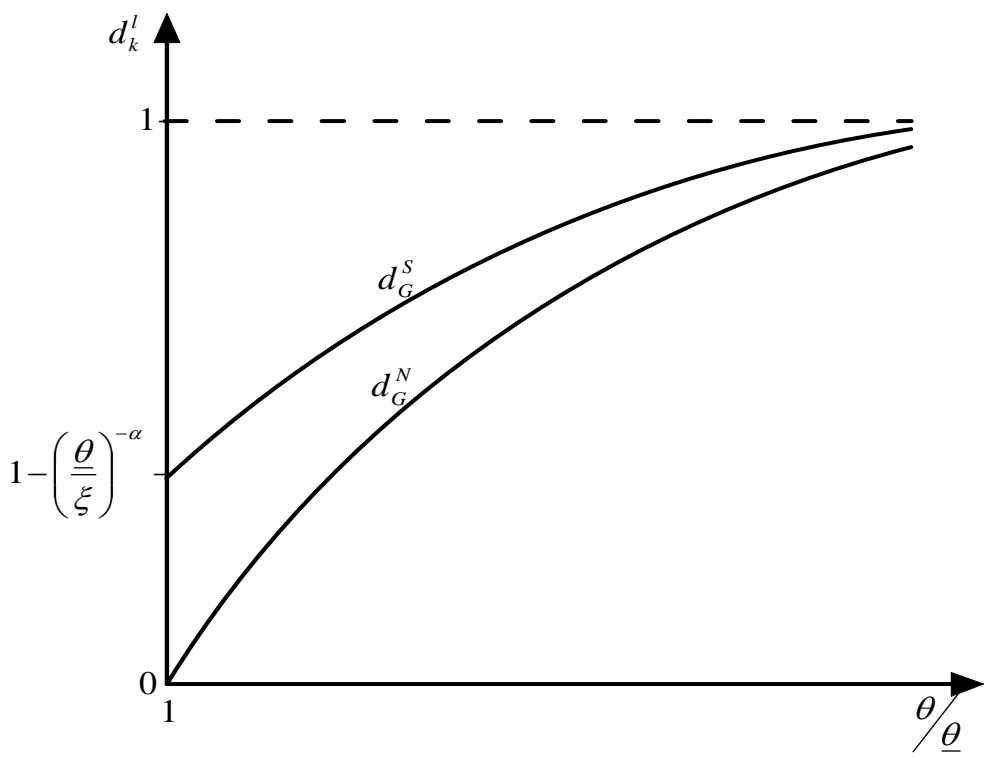

Figure 1: Degree of Input Specificity 


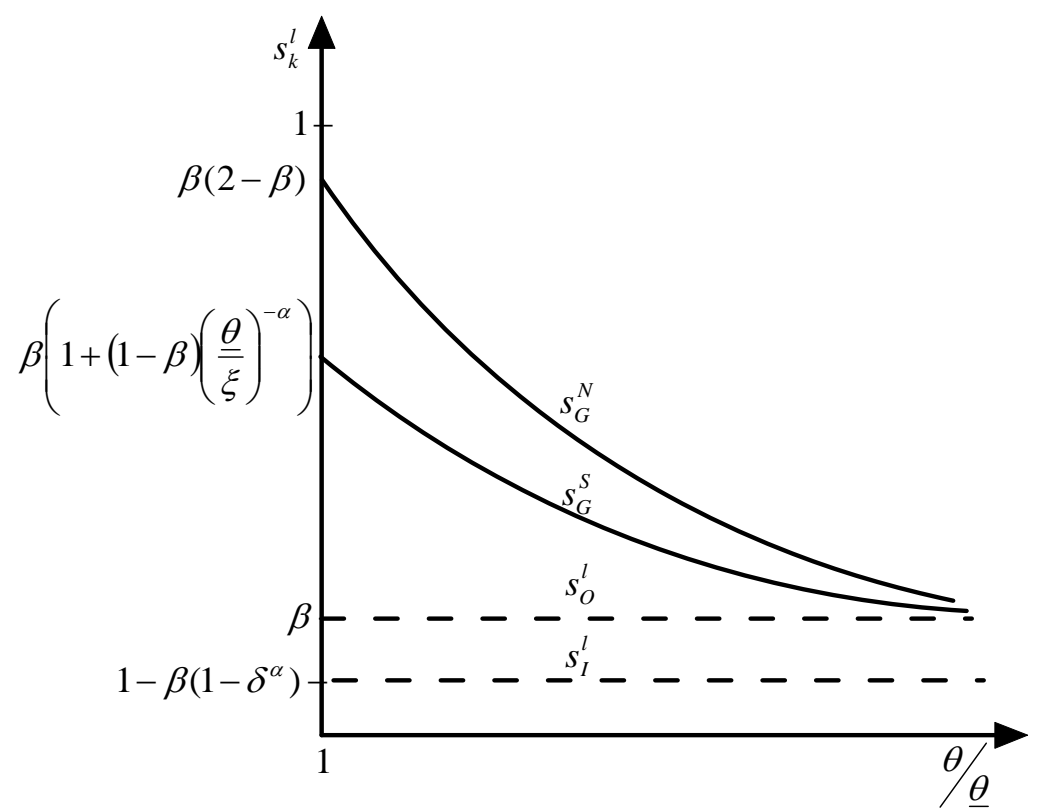

Figure 2: Intermediate good firm's ex post surplus share 


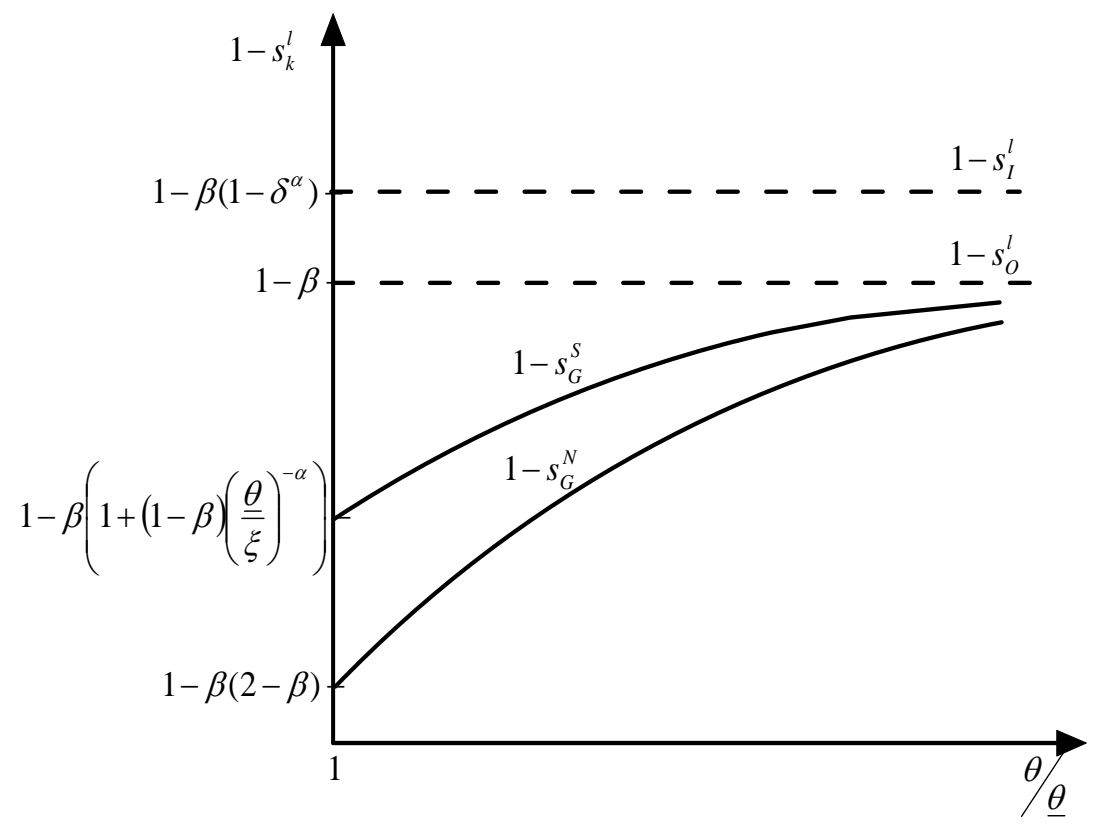

Figure 3: Hold-Up Friction 


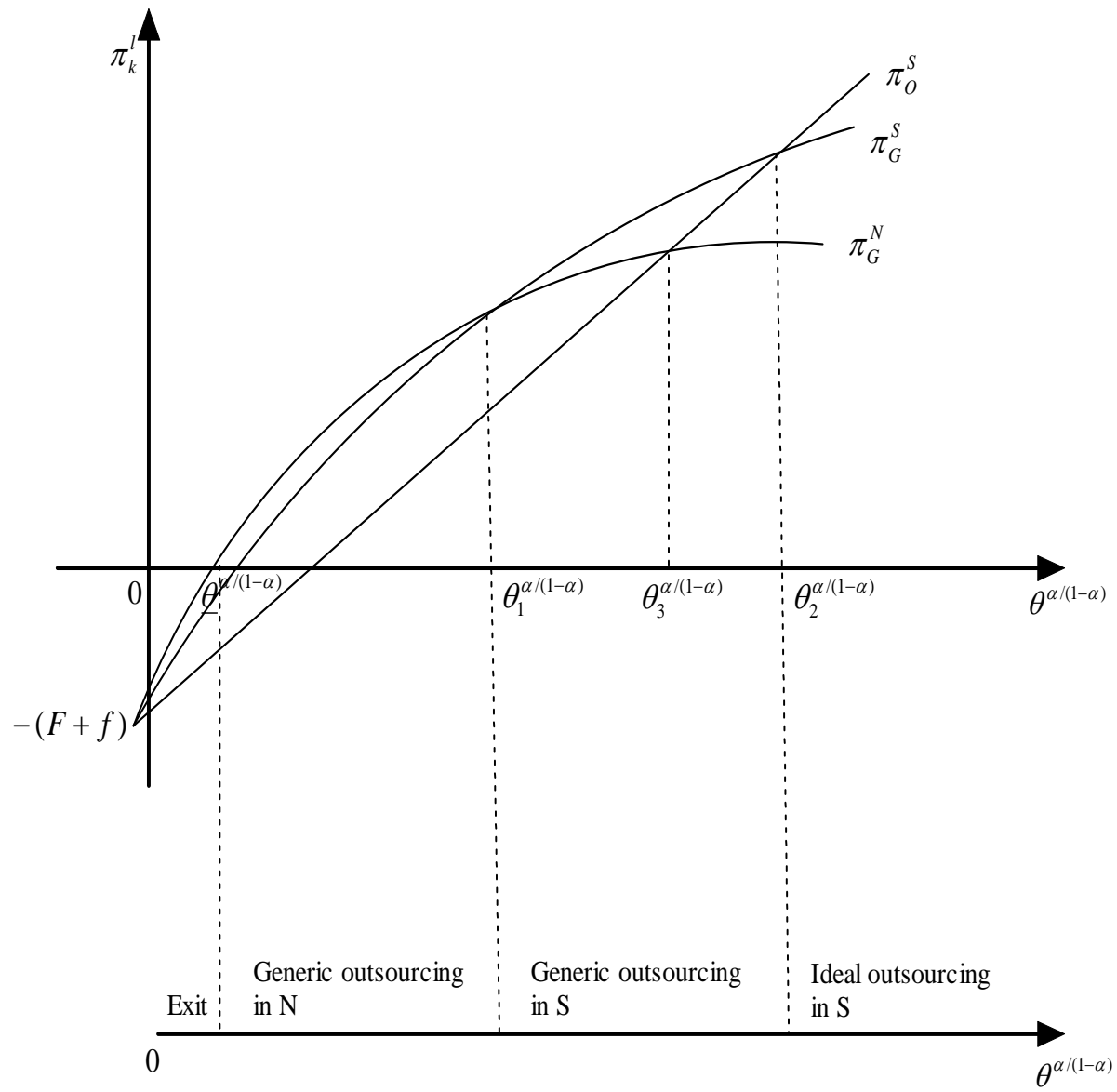

Figure 4: Equilibrium Organizational Form 